\title{
CARACTERIZAÇÃO DO EFLUENTE DE UMA USINA DE FABRICAÇÃO DE FERRO- LIGAS DE MANGANÊS
}

\author{
A. C. SILVA ${ }^{1}$, E. L. REIS ${ }^{1 *}$ e A. S. LOPES \\ ${ }^{1}$ Universidade Federal de Ouro Preto \\ ${ }^{2}$ VALE/Manganês \\ erica@demin.ufop.br
}

Artigo submetido em novembro/2013 e aceito em abril/2015

DOI: $10.15628 /$ holos.2015.1767

\section{RESUMO}

$\mathrm{Na}$ fabricação de ferro-ligas de manganês, são gerados efluentes líquidos advindos, principalmente, de calhas de drenagem hídrica dos pátios de estocagem de matéria-prima, produto e resíduos. Partículas com dificuldade de decantação natural, podem conferir à água características de turbidez e cor. Deste modo, o presente trabalho teve como finalidade a caracterização do efluente e da água tratada do tanque de decantação de uma usina de fabricação de ferro-ligas. As características examinadas foram: turbidez, sólidos totais (ST), sólidos em suspensão (SS), sólido dissolvidos (SD), pH, Eh, DQO e análise química. A turbidez antes do tratamento foi de 417 NTU e, após a passagem pelo tanque, obteve-se valor igual a $44 \mathrm{NTU}$, valor superior aos padrões de emissão para classe 1 regulamentados pela legislação ambiental brasileira em vigor (Resolução CONAMA $\left.n^{\circ} 357 / 2005\right)$. Os valores de ST, SS e SD do efluente foram iguais a 225, 114,3 e $110 \mathrm{mg} / \mathrm{L}$, respectivamente. Na água tratada os valores foram de 93, 48,3 e $45 \mathrm{mg} / \mathrm{L}$ para ST, SS e SD, respectivamente. O processo de decantação foi capaz de reduzir até $21 \%$ da DQO. As concentrações dos elementos $\mathrm{Al}, \mathrm{Mn}$ e $\mathrm{S}$ estão acima dos valores máximos permitidos pela Resolução $n^{\circ} 357$ de 2005 do CONAMA.

PALAVRAS-CHAVE: efluente, caracterização, ferro-ligas de manganês

\section{CHARACTERISTICS OF WASTEWATER FROM A PLANT FERROMANGANESE ALLOYS}

\begin{abstract}
In the manufacturing units ferromanganese alloys are generated wastewater arising mainly from gutters of drainage. This study aims to characterize the wastewater from the settling tank from a manufacturing plant of ferromanganese alloys. The main characteristics examined were: turbidity, total solids (TS), suspended solids (SS), dissolved solids (DS), $\mathrm{pH}, \mathrm{Eh}, \mathrm{COD}$ and chemical analysis. The turbidity before treatment was 417 NTU and after passing through the tank got value equal to $44 \mathrm{NTU}$, a figure slightly higher than the
\end{abstract}

emission standards for Class 1 regulated by the Brazilian environmental legislation in force (Dictum CONAMA no. $357 / 2005$ ). The values for TS, SS and DS of the effluent were equal to $225,114.3$ and $110 \mathrm{mg} / \mathrm{L}$, respectively. For the treated water the values were $93,48.3$ and 45 $\mathrm{mg} / \mathrm{L}$ for TS, SS and DS, respectively. The decantation process was able to reduce by $21 \%$ of the COD. The concentrations of the elements $\mathrm{Al}, \mathrm{Mn}$ and $\mathrm{S}$ were above the maximum permitted by Resolution no. 357 of 2005 of CONAMA.

KEYWORDS: wastewater, characterization, ferromanganese alloys 


\section{INTRODUÇÃO}

As normas redigidas pelos órgãos ambientais, que foram se tornando cada vez mais restritivas, estabelecem padrões de enquadramento para os resíduos e efluentes a serem descartados no meio ambiente. Com o objetivo de avaliar se um resíduo e/ou efluente necessita ou não de tratamento e, caso necessário, qual o procedimento mais adequado, é imprescindível que se realize a caracterização do mesmo, a qual é obtida a partir de diversos testes que mensuram o teor de poluição.

Com base na discussão anterior, procedeu-se à caracterização do efluente de uma usina de fabricação de ferro-ligas de manganês da região de Ouro Preto - MG, a qual apresentou em 2010, segundo dados internos da empresa, uma produção de aproximadamente 62 mil toneladas de ferro-ligas, constituindo-se, portanto, uma empresa de grande importância para o setor e que gera, também, uma quantidade significativa de rejeições.

Os efluentes da usina são provenientes de calhas de drenagem hídrica de pátios de estocagem de matéria-prima, produtos e rejeitos e também, do resfriamento da escória. Essas calhas conduzem os resíduos até um tanque de decantação de aproximadamente $1200 \mathrm{~m}^{2}$, o qual funciona em três etapas: enchimento, esgotamento e limpeza, que ocorre quando a espessura do resíduo sólido presente no fundo do tanque é igual a 0,4 $\mathrm{m}$. Foi realizada a caracterização do efluente bruto, isto é, do material que chega ao tanque de decantação e também do efluente tratado, ou seja, da água que é despejada no corpo receptor. A partir da comparação entre os resultados das amostras, foi possível a avaliação da eficiência do tanque de decantação utilizado e também, se água tratada a ser descartado apresentava parâmetros físicos e químicos que se enquadravam nas normas exigidas pela Resolução n 357 de 2005 do CONAMA.

Há grande preocupação no período chuvoso, quando aumenta a carga de partículas carreadas pelas águas que passam pelo tanque de sedimentação da referida empresa. As partículas do tanque em questão variam desde as coloidais, que sedimentam muito vagarosamente, até aquelas grosseiras, que se arrastam ao longo da corrente por distâncias que dependem de suas dimensões, no tanque de decantação da usina não são utilizados atualmente agentes coagulantes e/ou floculantes. A alta concentração de partículas de dimensões coloidais é responsável pela turbidez persistente e pela coloração das águas.

Dependendo das características do efluente tratado poderá haver assoreamento e poluição por materiais tóxicos e, consequentemente, comprometimento da fauna e da flora do manancial hídrico local. Portanto, o presente trabalho teve como objetivo caracterizar o tratamento utilizado no tanque de decantação da usina de fabricação de ferro-ligas de manganês como forma de avaliação da eficiência do processo utilizado.

\section{MATERIAIS E MÉTODOS}

As amostras foram coletadas no período chuvoso e armazenados sob resfriamento para uso em análises posteriores. $\mathrm{O} \mathrm{pH}$ foi medido utilizando potenciômetro da marca Digimed, modelo DM-22. O potencial redox (Eh) foi obtido a partir de um condutivímetro portátil da marca 
Instrutherm. As medidas de turbidez foram realizadas a partir do turbidímetro de marca Alfakit, com faixa de medição de 0 a 1000 NTU.

As concentrações de Sólidos Totais (ST) foram determinadas através da medida da massa de resíduos contida, após secura por 1 hora em estufa a $105^{\circ} \mathrm{C}$, em $100,00 \mathrm{~mL}$ de suspensão do efluente. A concentração de Sólidos Suspensos (SS) foi determinada por meio da massa de sólidos retidos no papel de filtro quantitativo, faixa azul, sendo que esses sólidos estavam presentes também em 100,00 mL de suspensão. Os sólidos dissolvidos foram determinados subtraindo-se a concentração de SS da concentração de ST standard methods (GUEDES, 2004).

Conforme SILVA e OLIVEIRA (2001), métodos titulométricos foram utilizados nas análises dos seguintes parâmetros: alcalinidade, cloreto, demanda química de oxigênio (DQO) e oxigênio dissolvido (OD). A alcalinidade foi determinada por titulometria da amostra, na presença dos indicadores fenolftaleína e metilorange, respectivamente, e o resultado encontrado foi expresso em função da concentração de carbonato de cálcio $\left(\mathrm{CaCO}_{3}\right)$.

A determinação da concentração de cloreto foi realizada a partir do método argentométrico, conhecido também como método de Mohr, no qual a amostra foi titulada, após o seu adequado pré-tratamento, com uma solução padrão de nitrato de prata. Durante essa titulação, os íons cloreto foram precipitados na forma de cloreto de prata, $\mathrm{AgCl}$. O indicador utilizado foi o cromato de potássio, $\mathrm{K}_{2} \mathrm{CrO} 4$, o qual formou, com um excesso de nitrato de prata, o precipitado vermelho de cromato de prata, $\mathrm{AgCrO}_{4}$.

O teste de demanda química de oxigênio (DQO) foi realizado a partir da oxidação da matéria orgânica por uma mistura de ácidos crômico e sulfúrico (dicromato de potássio, $\mathrm{K}_{2} \mathrm{Cr}_{2} \mathrm{O}_{7}$, em meio ácido). A determinação foi possível a partir da titulometria indireta, isto é, ocorreu por meio da titulação do excesso de $\mathrm{K}_{2} \mathrm{Cr}_{2} \mathrm{O}_{7}$ presente na solução que sofreu oxidação com solução padrão de sulfato ferroso amoniacal 0,025 N em presença do indicador ferroína.

A determinação de oxigênio dissolvido (OD) foi realizada a partir do método iodométrico, também conhecido como método de Winkler. Nesse procedimento, foi adicionada à amostra solução de manganês bivalente $\left(\mathrm{Mn}^{2+}\right)$ seguido de base forte, sendo que, sob condições alcalinas, o oxigênio fez o $\mathrm{Mn}^{2+}$ passar a $\mathrm{Mn}^{4+}$. Com a adição, em seguida, de íons iodeto em meio ácido, o manganês oxidado voltou ao estado bivalente liberando uma quantidade de iodo equivalente à concentração inicial de oxigênio dissolvido. O iodo foi titulado com solução padronizada de tiossulfato de sódio $\left(\mathrm{Na}_{2} \mathrm{~S}_{2} \mathrm{O}_{3}\right)$ na presença do indicador amido, sendo, portanto, um método titulométrico indireto.

Os elementos majoritários presentes nas amostras foram quantificados por espectroscopia de emissão atômica. O equipamento utilizado nas análises foi o espectrofotômetro de emissão atômica com fonte plasma da marca Spectro, modelo Ciros CCD.

Na tabela I estão apresentados os valores dos parâmetros analisados para os efluentes bruto e tratado.

\section{RESULTADOS E DISCUSSÃO}

Na tabela 1 estão apresentados os valores dos parâmetros analisados para os efluentes bruto e tratado. Os resultados encontrados para o efluente bruto e para o efluente tratado foram 
comparados entre si para se verificar a eficiência do tanque de decantação. Alguns resultados obtidos para o efluente tratado foram comparados com os padrões de emissão para classe 1 regulamentados pela legislação ambiental brasileira em vigor (Resolução $n^{\circ} 357$ de 2005 do CONAMA).

Tabela 1 - Análises físico-químicas e o desvio-padrão dos efluentes bruto e tratado do tanque de decantação de uma usina de fabricação de ferro-ligas de manganês e parâmetros CONAMA 357/2005.

\begin{tabular}{|c|c|c|c|}
\hline PARÂMETROS & EFLUENTE BRUTO & EFLUENTE TRATADO & $\begin{array}{c}\text { CONAMA } \\
\mathbf{3 5 7 / 2 0 0 5}\end{array}$ \\
\hline pH & $8,22 \pm 0,00$ & $7,80 \pm 0,14$ & $6,0 \mathrm{a} 9,0$ \\
\hline ST & $(225,0 \pm 3,6) \mathrm{mg} \cdot \mathrm{L}^{-1}$ & $(93,0 \pm 5,2) \mathrm{mg} \cdot \mathrm{L}^{-1}$ & - \\
SS & $(114,3 \pm 25,9) \mathrm{mg} \cdot \mathrm{L}^{-1}$ & $(45,0 \pm 5,8) \mathrm{mg} \cdot \mathrm{L}^{-1}$ & $\leq 500 \mathrm{mg} \cdot \mathrm{L}^{-1}$ \\
\hline SD & $(110,8 \pm 29,4) \mathrm{mg} \cdot \mathrm{L}^{-1}$ & $(48,3 \pm 7,1) \mathrm{mg} \cdot \mathrm{L}^{-1}$ & $\leq 40 \mathrm{NTU}$ \\
\hline Turbidez & $(416,71 \pm 0,37) \mathrm{NTU}$ & $(43,90 \pm 0,11) \mathrm{NTU}$ & - \\
\hline Eh & $(174,0 \pm 2,9) \mathrm{mV}$ & $(104,7 \pm 0,3) \mathrm{mV}$ & - \\
\hline Alcalinidade & $(91,7 \pm 0,3) \mathrm{mg} \cdot \mathrm{L}^{-1} \mathrm{CaCO}$ & $(94,8 \pm 0,8) \mathrm{mg} \cdot \mathrm{L}^{-1} \mathrm{CaCO}_{3}$ & - \\
\hline DQO & $(61,4 \pm 3,8) \mathrm{mg} \cdot \mathrm{L}^{-1} \mathrm{O}_{2}$ & $(48,0 \pm 4,2) \mathrm{mg} \cdot \mathrm{L}^{-1} \mathrm{O}_{2}$ & $\geq 6 \mathrm{mg} \cdot \mathrm{L}^{-1} \mathrm{O}_{2}$ \\
\hline OD & $(14,0 \pm 0,1) \mathrm{mg} \cdot \mathrm{L}^{-1} \mathrm{O}_{2}$ & $(12,4 \pm 0,1) \mathrm{mg} \cdot \mathrm{L}^{-1} \mathrm{O}_{2}$ & $\leq 250 \mathrm{mg} \cdot \mathrm{L}^{-1} \mathrm{Cl}$ \\
\hline Cloreto & $(2,7 \pm 0,9) \mathrm{mg} \cdot \mathrm{Ll}^{-1} \mathrm{Cl}$ & $(3,8 \pm 0,5) \mathrm{mg} \cdot \mathrm{L}^{-1} \mathrm{Cl}^{-}$ & $\leq$ \\
\hline
\end{tabular}

Comparando-se os valores de $\mathrm{pH}$ obtidos para o efluente bruto e para o tratado, não ocorreu grande variação sendo que o valor permaneceu em torno de 8 , isto é, o valor do $\mathrm{pH}$ de ambos são próximos da neutralidade. Para haver enquadramento na classe $1,0 \mathrm{pH}$ deve estar entre 6,0 e 9,0 .

Em relação à alcalinidade, que equivale à soma das bases tituláveis, pode-se dizer que não há variação significativa entre os valores dos efluentes bruto, $(91,7 \pm 0,319) \mathrm{mg} \cdot \mathrm{L}^{-1} \mathrm{CaCO}_{3}$, e

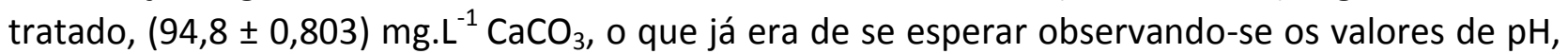
que não apresentam diferença significativa. A maioria das águas naturais apresentam valores de alcalinidade entre 30 e $500 \mathrm{mg} / \mathrm{L}$ de $\mathrm{CaCO}_{3}$, o efluente a ser descartado encontra se nessa faixa. Silva et al. (2014) identificaram como constituintes dos sólidos sedimentados no fundo do tanque de decantação deste estudo as seguintes fases minerais: quartzo, muscovita, caulinita, calcita e albita. Deste modo a quantidade representativa de alcalinidade parece ser em parte atribuída a fases como a calcita.

Antes do tratamento, a turbidez, originada de materiais insolúveis, isto é, em suspensão, foi de 417 NTU e, após a passagem pelo tanque de decantação, o valor foi igual a 44 NTU. Segundo a Resolução $n^{\circ} 357$ de 2005 do CONAMA, para água doce classe 1, é permitido um valor máximo igual a 40 NTU. $O$ valor de turbidez encontrado está muito próximo ao especificado pela norma, este parâmetro está diretamente relacionado ao número de partículas presentes e tem um significado ambiental importante por razões de natureza diferentes: estéticas, de filtrabilidade e de desinfeç̧ão.

Os valores de sólidos totais para os efluentes bruto e tratado foram, respectivamente, $225,0 \mathrm{mg} . \mathrm{L}^{-1}$ e $93 \mathrm{mg} . \mathrm{L}^{-1}$. Portanto, após tratamento, houve redução de aproximadamente $59 \%$ dos sólidos totais. Em relação aos sólidos totais presentes, pode-se dizer que, aproximadamente $50 \%$ deles correspondem a sólidos suspensos (SS) e $50 \%$ a sólidos dissolvidos (SD), tabela 1 , ou seja, a relação entre sólidos filtráveis e sólidos em fino estado coloidal é muito próxima. Em relação aos sólidos suspensos, houve redução de aproximadamente $61 \%$. De acordo com a 
Resolução $\mathrm{n}^{\circ} 357$ de 2005 do CONAMA, é permitido uma concentração máxima igual a $500 \mathrm{mg} \cdot \mathrm{L}^{-1}$ de SD, portanto, o efluente se encontra dentro das normas quanto a esse quesito, já que a concentração de SD encontrada para o efluente tratado foi igual a $48,3 \mathrm{mg}$. $\mathrm{L}^{-1}$. De modo geral, os sólidos suspensos de maiores dimensões, conseguem ser removidos parcialmente nos decantadores primários. Deste modo, provavelmente predomina na amostra de SS partículas grosseiras, sólidos sedimentáveis, que sedimentam com maior facilidade.

Os valores de OD encontrados para o efluente antes e após a passagem pelo tanque de decantação foram 14 e 12,4 mg. $\mathrm{L}^{-1}$ de $\mathrm{O}_{2}$, respectivamente. De acordo com a Resolução $\mathrm{n}^{\circ} 357$ de 2005 do CONAMA, o valor mínimo permitido para a água de classe 1 é igual a $6 \mathrm{mg} \cdot \mathrm{L}^{-1}$ de $\mathrm{O}_{2}$. É de extrema importância a determinação do valor de OD na avaliação da qualidade das águas já que o oxigênio está envolvido em praticamente todos os processos químicos e biológicos. No caso da vida aquática, por exemplo, conforme SANTOS (2008), a exposição a concentrações menores do que $2 \mathrm{mg} \cdot \mathrm{L}^{-1}$ de $\mathrm{O}_{2}$, pode levar os organismos à morte. Em relação à DQO, foi obtido, após tratamento, uma diminuição de aproximadamente $22 \%$, ou seja, houve redução de poluentes. Parece ocorrer processos de oxidação que levam a diminuição da DQO. Os valores de Eh confirmam a tendência oxidante do meio. O meio com esta características parece ter contribuído na diminuição dos sólidos dissolvidos, contribuindo para reatividade do meio, já que o processo de tratamento consiste apenas de decantação simples sem a utilização de polieletrólitos.

A concentração máxima de cloreto permitida é $250 \mathrm{mg} \cdot \mathrm{L}^{-1}$, portanto a concentração desse componente no efluente tratado, 3,8 mg. $\mathrm{L}^{-1}$, está bem abaixo do valor máximo permitido pela norma. Altas concentrações de $\mathrm{Cl}^{-}$provocam sabor salgado à água, podem causar corrosão de estruturas metálicas e apresentam influência negativa nos ecossistemas aquáticos por provocar alteração da pressão osmótica em células de micro-organismos, sendo, portanto, um parâmetro que sempre deve ser mensurado em caracterizações (SANTOS, 2008).

$\mathrm{Na}$ tabela 2 estão apresentados os teores dos elementos majoritários presentes no efluente bruto e na água tratada do tanque de decantação da usina de fabricação de ferro-ligas.

Tabela 2 - Elementos majoritários dos efluentes bruto e tratado do tanque de decantação da usina de fabricação de ferro-ligas de manganês da região de Ouro Preto - MG e parâmetros do CONAMA.

\begin{tabular}{|c|c|c|c|c|c|c|c|c|c|}
\hline & Al & Ba & Ca & Cu & Fe & K & Mn & S & Sr \\
(mg/L)
\end{tabular}

Não houve variação significativa na concentração dos elementos após tratamento, com exceção do ferro e alumínio. Isso provavelmente é devido a uma espécie de pré-concentração das fases portadoras dos elementos na água tratada.

A Resolução $n^{\circ} 357$ do CONAMA estabelece valores máximos permitidos para concentrações de alguns elementos em águas de classe 1. Comparando-se os valores encontrados para o efluente tratado com o que é exigido pela norma, é possível afirmar que a 
concentrações de Al encontra-se acima, tendo em vista que o valor máximo permitido para esse elemento é, $0,1 \mathrm{mg} / \mathrm{L}$. O valor de Fe no tratado encontra-se no valor máximo permitido na classe $1(0,3 \mathrm{mg} / \mathrm{L})$.

Para os elementos $\mathrm{Mn}$ e $\mathrm{S}$, os valores máximos permitidos pela Resolução $\mathrm{n}^{\circ} 357$ do CONAMA são $0,1 \mathrm{mg} / \mathrm{L}$ e $0,002 \mathrm{mg} / \mathrm{L}$, respectivamente. Portanto, as concentrações encontradas para o efluente tratado são superiores ao que é permitido, sendo que a concentração de $\mathrm{Mn}$, $0,8 \mathrm{mg} \cdot \mathrm{L}^{1}$, é cerca de oito vezes maior do que o exigido pela norma; e a de $\mathrm{S}, 0,008 \mathrm{mg} \cdot \mathrm{L}^{-1}$, é aproximadamente quatro vezes maior. No solo da região, não é característico a presença de $\mathrm{Mn}$, portanto, como o efluente é gerado em uma usina produtora de ferro-ligas de manganês, é possível afirmar que ele possivelmente vem das matérias-primas, dos finos da liga produzida e/ou da escória (REIS, 2010).

O bário encontra-se em concentração abaixo do limite exigido pela legislação ambiental (Resolução $n^{\circ} 357$ do CONAMA) que estabelece também limites para os metais pesados $\mathrm{Hg}, \mathrm{Cr}$, $\mathrm{Cu}$, mas suas concentrações não foram mensuradas na análise, pois estão em teores menores do que o limite quantificado pelo ICP-OES. Portanto, como o limite de quantificação do aparelho é baixo $\left(0,009 \mathrm{mg} \cdot \mathrm{L}^{-1}\right.$ e $0,004 \mathrm{mg} \cdot \mathrm{L}^{-1}$ para $\mathrm{Cr}$ e Cu, respectivamente), pode-se afirmar que o efluente a ser descartado no corpo receptor não apresenta toxicidade causada por $\mathrm{Ba}, \mathrm{Hg}, \mathrm{Cr}$ ou $\mathrm{Cu}$.

\section{CONCLUSÕES}

- O efluente tratado encontra-se dentro dos valores estabelecidos para água classe 1 da Resolução $\mathrm{n}^{\circ} 357$ do CONAMA quanto aos parâmetros pH, concentração de sólidos dissolvidos, oxigênio dissolvido (OD) e concentração de cloreto $\left(\mathrm{Cl}^{-}\right)$.

- O valor de turbidez obtido para o efluente tratado, 44 NTU, ainda se encontra acima do valor máximo permitido pelo CONAMA para águas enquadradas na classe 1 . Desse modo, é necessário melhorar o tratamento, o que pode ser feito a partir de testes nos quais se adiciona agentes auxiliares no processo de separação sólido-líquido.

- As concentrações dos elementos Al, Mn e S, respectivamente, 0,2; 0,8 e 0,008 mg. $\mathrm{L}^{-1}$, estão um acima do que é exigido pela legislação.

- O efluente tratado não apresenta risco de contaminar o corpo receptor com metais pesados tais como $\mathrm{Ba}, \mathrm{Cr}, \mathrm{Cu}$ e $\mathrm{Hg}$, que é um resultado muito positivo, já que esses metais são extremamente tóxicos para os organismos vivos.

É necessário melhorar o tratamento para enquadramento de alguns parâmetros, conforme já citado, o que está sendo realizado pelo grupo de pesquisa.

\section{AGRADECIMENTOS}

Os autores agradecem ao CNPq, a UFOP, a Fundação Gorceix e a VALE/Manganês.

\section{REFERÊNCIAS BIBLIOGRÁFICAS}

1. CONAMA. Resolução CONAMA n 357/2005. Qualidade das águas. p. 280-303, 2005. 
2. GUEDES, C. D. Coagulação/floculação de águas superficiais de minerações de ferro com turbidez elevada. Ouro Preto, 2004. Programa de Pós-Graduação em Evolução Crustal e Recursos Naturais, Universidade Federal de Ouro Preto, 2004.

3. OHLWEILER, O. A. Química analítica quantitativa. Livros Técnicos e Científicos, Rio de Janeiro, 1974.

4. REIS, É. L. Caracterização e tratamento de alguns minérios de manganês utilizados para produção de ferro-ligas, com ênfase no comportamento do $\mathrm{As}, \mathrm{Pb}, \mathrm{Cd}, \mathrm{Hg}$ e $\mathrm{Zn}$. Ouro Preto,2010. Universidade Federal de Ouro Preto, Escola de Minas, 2010. Tese de Doutorado Engenharia de Materiais/REDEMAT- Escola de Minas - Universidade Federal de Ouro Preto).

5. REIS, É. L.; LENA, J. C.; GUEDES, C. D. A medição da turbidez contento partículas escuras (goethita e hematita). In: Anais do Encontro da Associação Brasileira de Química, 2003. v. 52, São Paulo, Associação Brasileira de Química.

6. SANTOS, E. S. caderno Pedagógico - Análises físico-químicas de águas e de solos. Universidade Tecnológica Federal do Paraná, Secretaria de Estado da Educação, Superintendência da Educação, Pinhais, Paraná, 2008.

7. SILVA, S. A. \& OLIVEIRA, R. Manual de Análises Físico-Químicas de Águas de Abastecimento e Residuárias. Campina Grande, DEC/CCT/UFPG, 2001.

8. SILVA, A. C.; REIS, É. L.; SILVEIRA, A. L. Wastewater characterization from a ferromanganese alloys plant. In: XXVII International Mineral Processing Congress -IMPC 2014. Santiago, Chile. 